\title{
Indian gatekeepers of foreign journals: A preliminary analysis
}

\author{
Vipan Kumar*, Rashmi Srivastava ${ }^{1}$ \\ CSIR-National Institute of Science Technology and Development Studies, New Delhi, 'Department of Forensic Medicine, \\ Institute of Medical Science, Banaras Hindu University, Varanasi, Uttar Pradesh, India
}

\begin{abstract}
In recent years, efforts have been made to quantify and measure various aspects of performance of a country by measuring both the quantity and quality of research. Recently, a new science indicator has been introduced of named as the "gatekeepers" or "members of editorial boards" to investigate the scientific/technological contribution of a country. The editorial boards of scientific journals play a crucial role in science by helping to guarantee the quality and relevance of the research eventually published. Besides, it can be assumed the presence on an editorial board of persons of a given nationality can influence the scientific output of their country, which could be made more visible. Until date, little explicit attention has been given to editorial board memberships of Indians despite such appointments being generally regarded as representing evidence of significant scholarship and research achievement by individual academics. The objective of this research is to contribute data on patterns of editorial board membership of Indian academics and journals. Specifically, we examine the composition and concentration of individuals on editorial boards in academic journals with high rankings. The study contributes to the best of our knowledge of Indian contribution in influencing the research at international level by means of gate-keeping.
\end{abstract}

Keywords: Editorial boards, gatekeeper, scientometrics, social network

\section{INTRODUCTION}

The research contribution of a nation is instrumental in developing the science research and development policy by a country. In recent years, efforts have been made to quantify and measure various aspects of performance of a country by measuring both the quantity and quality of research. The contribution of India in science research has been investigated in terms of scientometric parameters such as number of publications and citations of papers published in journals. ${ }^{[1-3]} \mathrm{A}$ citation is a reference made to work of an

*Address for correspondence:

E-mail: vipin.nistad@gmail.com

\begin{tabular}{|l|l|}
\hline \multicolumn{2}{|c|}{ Access this article online } \\
\hline Quick Response Code: & Website: \\
\hline & www.jscires.org \\
\cline { 2 - 3 } & \\
\hline
\end{tabular}

author in another scientific article as an acknowledgement of prior work. ${ }^{[4]}$ A high level of citation to an author's work is, in general, a testimony to the fact that the author's work has been noted and used by his peers. High citation is seen to be correlated with other forms of recognition and rewards and is a key indicator of research performance, among other bibliometric indicators. ${ }^{[4]}$ Basu (2006) made use of "highly cited researchers" and found it to provide a good indication of research performance of a country. ${ }^{[4]}$ Furthermore, number of publications has been utilized to know the scientific output of any country and is considered a valid marker of performance of a country's scientific and research activity. ${ }^{[5]}$ Analysis of publications provide some insight into the complex dynamics of research activity and enables policy makers and science administrators in framing policies and directions in which $\mathrm{R}$ and $\mathrm{D}$ has to be conducted. However, a different approach has been introduced in the form of a new science indicator named the "gatekeepers" or "members of editorial boards." The editorial boards of scientific journals play a crucial role in science by helping to guarantee the quality and relevance 
of the research eventually published. It is believed that the critical mentality of journal editors and the decisions they take protect the social and intellectual integrity of science. They are able to exert a special influence on the direction that research takes in a particular discipline. ${ }^{[6]}$ Normally, members of editorial boards are chosen after they have published a number of articles in very good journals, thus showing that they can judge the quality of the articles they review. Hence, the editorial board membership can be seen as an important indicator of individual academics' long-term research reputation that reflects his/her eminence in that research area and is considered as an honor. The distribution of researchers of a country as editorial members in the international journals has an element of national pride and the influential role, which they can play has important impact on individual careers as the board membership is generally considered to carry status for the academics involved, particularly for high quality journals. This may enhance an individual's personal prestige and also, by association, the reputation of their institutions. The editorial members are more likely, to belong to the country from which the editor of the journal comes from. This could be the outcome of the social network of the journal's editor which comprise his/her work and social contacts inside and outside of his/her organization, which enable him/her to secure benefits (such as editorial board membership or access to the editor) by virtue of his/her membership in those networks. ${ }^{[7]}$ Although the presence on an editorial board of persons of a given nationality does not directly imply that scientists of the same nationality will be more commonly published, the possibility exists that the scientific output of their country could be made more visible. ${ }^{[8]}$ In an article in 2006 Granadino et al. investigated the presence of Spanish scientists on the editorial boards of the top 100 journals and found a weak correlation between the editorial board members Spanish scientists might be improved if prestigious Spanish scientists were members of editorial boards. Later, same authors (Garcia-Carpintero et al. 2010) extended this study to analyses the nationalities of the editorial board members of the top 20 journals (according to their impact factor in the ISI Journal Citation Report, Science Edition 2005) serving 15 scientific disciplines. An interesting outcome of this study was that a significant correlation was observed between the scientific outputs by nationality in these journals, with the representation of the corresponding nations on the editorial boards.

Until date, little explicit attention has been given to editorial board memberships of Indians despite such appointments being generally regarded as representing evidence of significant scholarship and research achievement by individual academics. More particularly, we know little of the representation, which Indian academics have on the editorial boards of the journals. The objective of this research is to contribute data on patterns of editorial board membership of Indian academics and journals. Specifically, we examine the composition and concentration of individuals on editorial boards in academic journals with high rankings. The study contributes to our knowledge of Indian contribution in influencing the research at international level by means of gatekeeping.

\section{METHODOLOGY}

The sample for the present study is derived from "SCImago Journal Rank (SJR) indicator, developed by SCImago based on Google PageRank ${ }^{\mathrm{TM}}$ algorithm Scopus ${ }^{\circledR}$ database from 1996. Scopus is an international multidisciplinary database indexing over 19,000 international peer reviewed journals. By far Scopus is the single largest international multidisciplinary database in the world. Top 500 SJR journals were selected as our sample; the purpose of doing so was to have an insight of the Indian contribution in the top ranked journals as well as their general representation in the editorial boards of the selected journals. The information regarding the editorial boards of a journal was obtained directly from its website. In doing so, the persons holding the positions of editor-in chief, regional editor, senior editor, coordinating editor, executive editor, co-editor, honorary editor, founding editor, editorial adviser, associate editor, advisory committee member, advisory board member and publication committee member were identified as members of the editorial boards. The nationalities and affiliations were recorded. The final data was then computed by counting and country wise pooling of the editors. During the process few journals were identified, which have not provided the country name or affiliation of the member. Such journals were excluded from the study. Hence, our final data was comprised of 448 journals from the top listings of journals.

\section{Objectives}

\section{Top ranked journals}

To build up a country wise distribution of membership of editorial boards in the top 500 journals and to investigate the presence of Indians in the editorial boards of high quality journals. 


\section{Subject-area wise analysis}

To study the pattern of distribution of Indian editorial members in the journals according to the subject areas or fields.

\section{Correlation between a country's scientific output and the number of editorial board}

To study the correlation between countries' scientific output in a journal w.r.t. the number of editorial board members of that country in that particular journal.

\section{RESULTS}

\section{Top Ranked Journals}

Figure 1 shows that the top 448 journals (by SJR) were represented only six countries, i.e. USA, UK, Netherlands, Germany, Denmark, Switzerland and China. More than $56 \%$ of top 448 journals were published in the Unites States followed by the United Kingdom (34\%). One journal i.e. "Nano Research" published in China was observed in top 448 journals. No Indian journal was present in the top 500 journals.

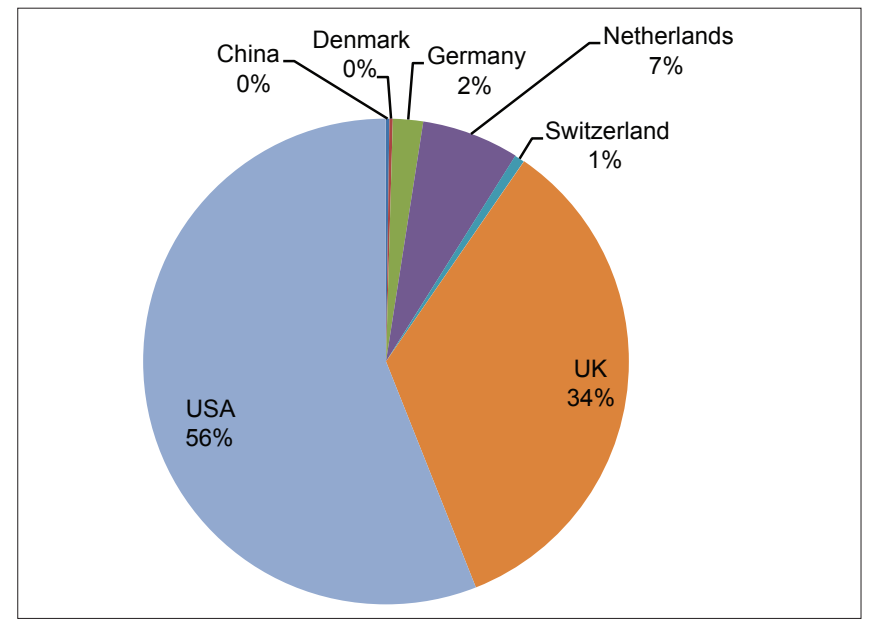

Figure 1: Percentage of journals by country in the top 448 journals
Figure 2 represents the distribution of the editorial members of different countries in top 448 journals. A total of 14036 editorial board members were identified for total 448 journals analyzed - an average of $31.33 \%$ editorial member per journal. It is clear that the editorial boards were dominated by the individuals from United States representing $62.06 \%$ of the total.

Number of editorial members followed by UK (8.49\%). Members from India comprised of only $0.30 \%$ i.e. the lowest among all the studied countries. Japan and China were ahead from India in representing the editorial board members $(1.77 \%$ and $1.94 \%$, resp.). Indian individuals affiliated outside the country contributed $1.93 \%$. Since, more than $50 \%$ of top 448 .

Journals were from USA, it was obvious that the members from USA were found maximum. For this reason, the journals were analyzed by dividing it into two groups i.e. US journals and non-US journals. However, the scenarios remained similar. The USA members dominated both the US as well as non-US journals.

The country wise distribution of editorial members in the studied top 448 journals is given in Table 1. It is clear that the members from USA were present in large numbers in

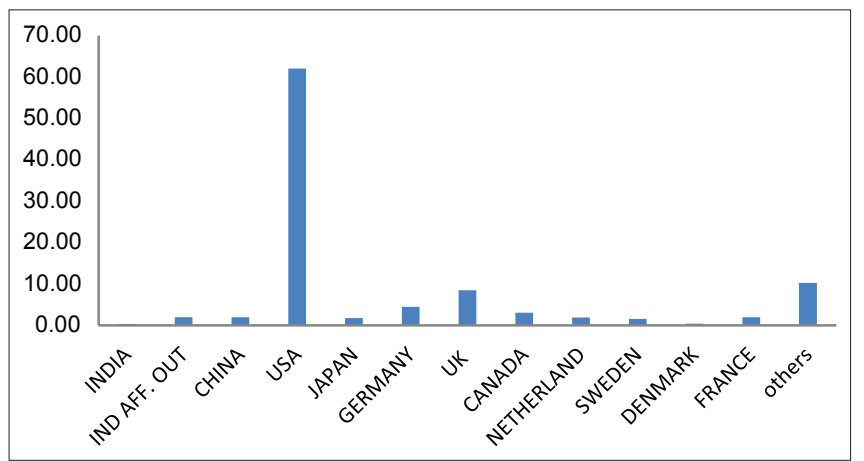

Figure 2: Percentage of editorial board members of different countries in the studied 448 journals

Table 1: Editorial composition of top 448 journals (country wise)

\begin{tabular}{|c|c|c|c|c|c|c|c|c|c|c|c|c|c|c|}
\hline $\begin{array}{l}\text { Publication } \\
\text { country }\end{array}$ & India & $\begin{array}{c}\text { Indians } \\
\text { affiliated out }\end{array}$ & China & USA & Japan & Germany & UK & Canada & Netherland & Sweden & Denmark & France & $\begin{array}{c}\text { Otherl } \\
\text { Romania }\end{array}$ & Total \\
\hline China & 0 & 0 & 15 & 22 & 0 & 1 & 0 & 0 & 1 & 0 & 0 & 0 & 2 & 41 \\
\hline Denmark & 1 & 0 & 0 & 40 & 4 & 4 & 11 & 2 & 1 & 0 & 0 & 3 & 11 & 77 \\
\hline Germany & 0 & 2 & 16 & 97 & 9 & 34 & 22 & 6 & 7 & 8 & 0 & 11 & 31 & 243 \\
\hline Netherlands & 3 & 26 & 23 & 505 & 43 & 55 & 77 & 32 & 21 & 25 & 6 & 23 & 140 & 979 \\
\hline Switzerland & 1 & 0 & 1 & 12 & 0 & 11 & 4 & 1 & 0 & 1 & 1 & 1 & 13 & 46 \\
\hline UK & 13 & 47 & 121 & 2540 & 103 & 208 & 684 & 142 & 125 & 88 & 20 & 131 & 609 & 4831 \\
\hline USA & 24 & 196 & 97 & 5495 & 89 & 310 & 394 & 247 & 107 & 96 & 23 & 108 & 633 & 7819 \\
\hline Total & 42 & 271 & 273 & 8711 & 248 & 623 & 1192 & 430 & 262 & 218 & 50 & 277 & 1439 & 14036 \\
\hline
\end{tabular}


almost all the journals of different countries. The maximum number was in the journals of USA itself, followed by the journals of UK and Netherlands. A total of 32 Indians were identified to be present in the top 448 journals and 271 Indians affiliated with other countries were identified. The members from India were present in the journals of all the countries represented in top 448 journals except Germany. The maximum number of Indians (24) was present in journals of United States followed by the journals of UK (13). The same was observed for Indians affiliated outside India. Members of China and Japan shared the editorial boards of journals of USA and UK fairly well and better than India.

Figure 3 shows the composition of journals of six publication countries. It is clear from the figure that proportion of USA members in editorial boards of the top 448 journals was highest, irrespective of the publication country of the journals. The proportion of Indian members was among the lowest when compared with other Asian countries i.e. China and Japan. Indians affiliated outside or with foreign countries were present in fair numbers in the journals of USA, UK and Netherlands.

Figure 4 shows the comparison of distribution of editorial board members of India, Indians affiliated out and China.
Data shows that members of USA and UK are distributed well in the journals of wide range of SJRs (not represented in the figure because of legibility). The presence of Indian editorial board members remained at lower most SJRs. Individuals from France and Germany are also present in the journals of high SJRs. Non Resident Indian's (NRIs) are performing much better than the researchers from India. NRI's representation among top 500 journals is widely distributed among all SJR levels.

\section{Classification of Journals}

Titles in Scopus are classified under four broad subject clusters (Life Sciences, Physical sciences, Health Sciences and Social Sciences and Humanities) which are further divided into 27 major subject areas. However, Journal titles may belong to more than one subject area i.e. multidisciplinary. Figure 5 shows the division of top 448 journals into broad subject fields. Most of the top 448 journals were from the field of life sciences $(26 \%)$, followed by the journals of physical sciences $(22 \%)$, about $23 \%$ journals were multidisciplinary.

Figure 6 shows the proportion of editorial board membership of different countries in each subject field. Clearly, USA and UK are ahead in contributing through their membership in the editorial board of the journals of each subject field. If

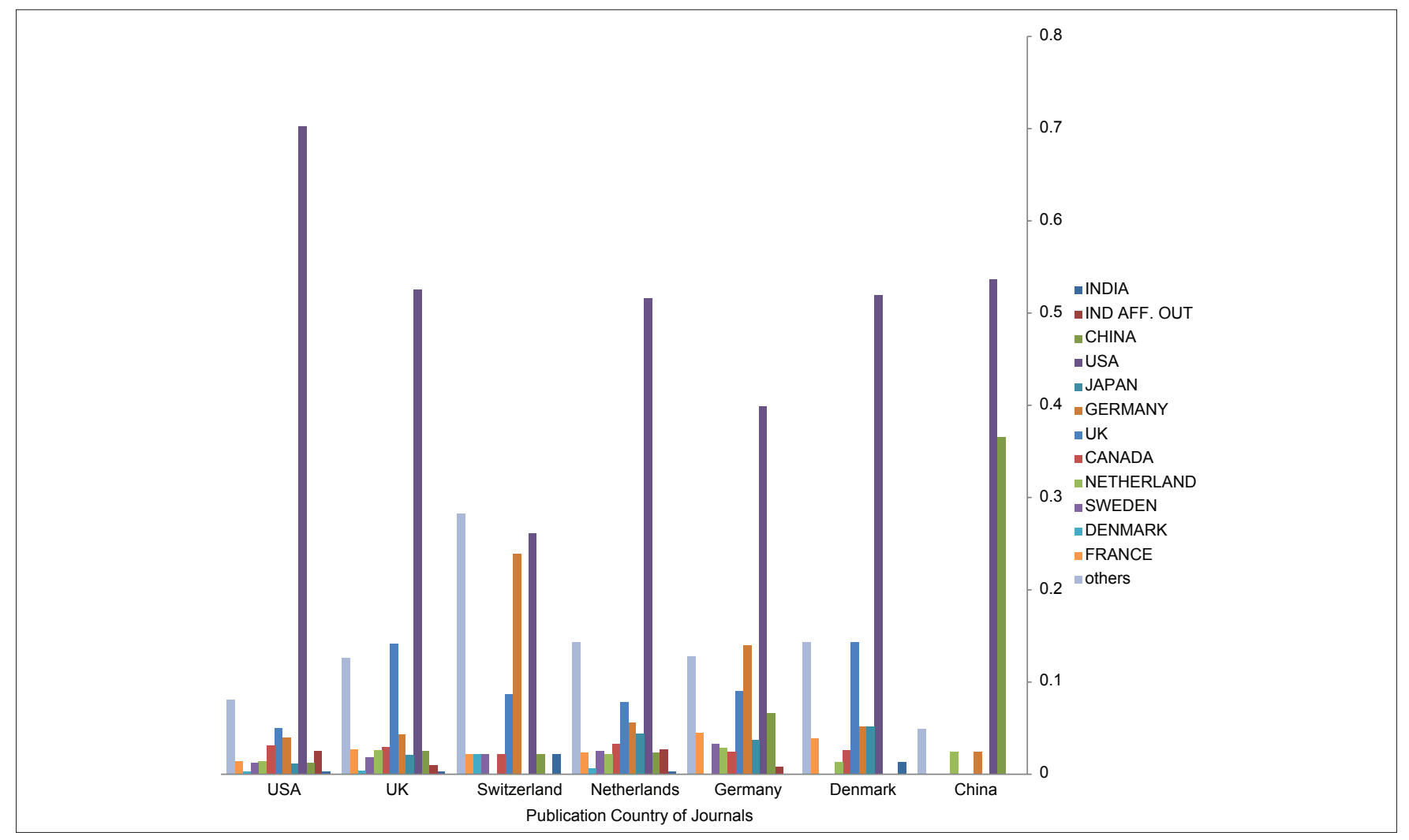

Figure 3: The composition of editorial board of journals 
we consider India's role, the scenario is appreciating. A good number of Indians were observed to be present in the editorial boards of the journals of Health Sciences and Life Sciences. In fact, their presence is much better than some

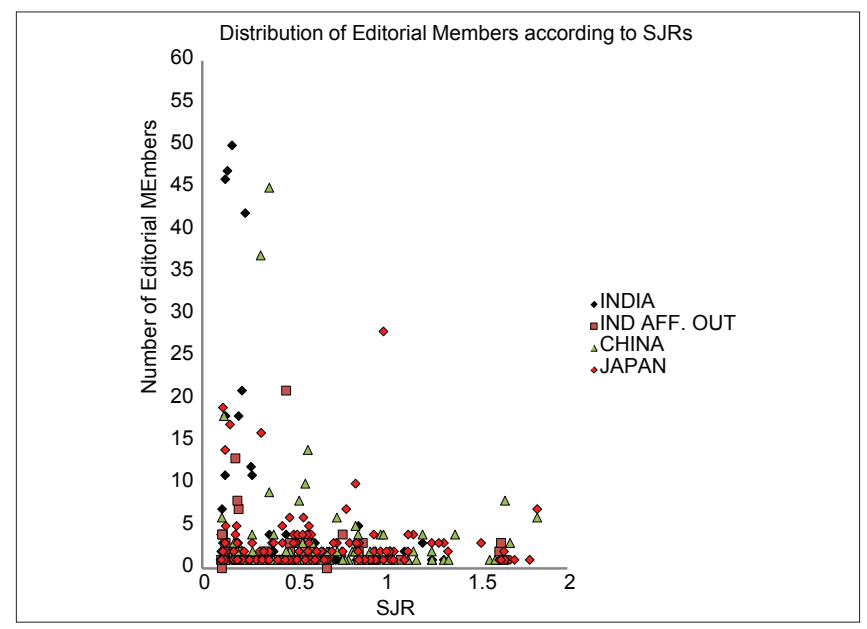

Figure 4: Distribution of editorial board members of different countries in the journals of different SCImago Journal Ranks

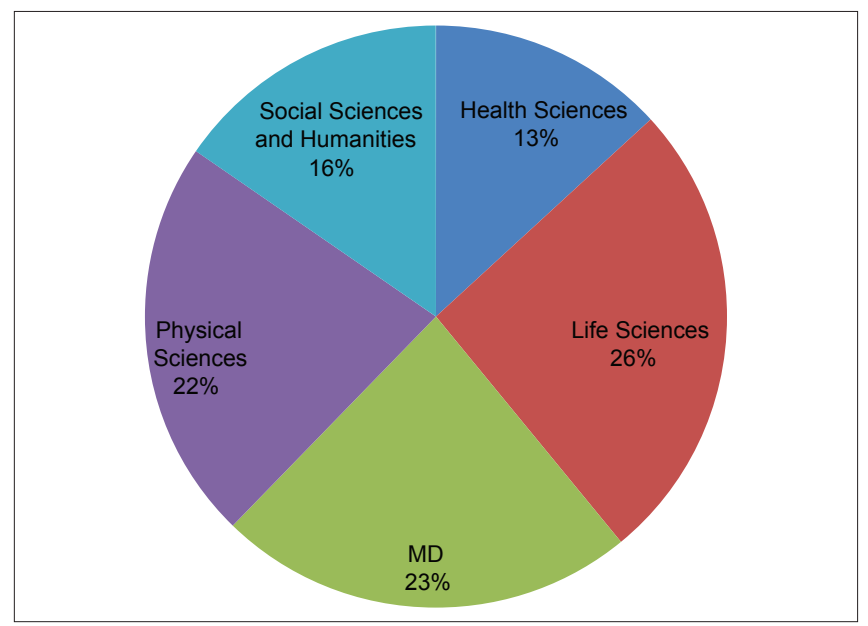

Figure 5: Subject filed wise classification of Journals of the other countries such as China, Germany, Canada, Netherland, Sweden, Denmark, France Australia and Italy. However, in the fields of Physical Sciences and Social Sciences and Humanities, the results are not so encouraging.

The contribution of Indians in each field is depicts in Figure 7. It shows that members from India were present in high percentage $(57 \%)$ in the field of physical sciences followed by the field of life sciences (26\%). However, Indians who were affiliated outside or with foreign countries mostly worked in the field of Social Sciences and Humanities (43\%).

\section{Correlation: Presence Versus Output}

Finally, when correlations were sought between total number of members of a country present in the editorial boards of 253 journals (studied countries) of the random sample and the scientific output of the corresponding country for the year 2011, a strong correlation was found between countries from which board members came and the scientific output of that Country the best fit being logarithmic $(R=0.990)$ [Figure 8].

\section{CONCLUSIONS}

The paper is a brief analysis of a sample of 500 Journals from SJR indicator. The information regarding the editorial board members was taken directly from the journal website. The information about the country of origin was also judged based on the affiliation. NRI status was given to the person with the Indian name and foreign affiliation. It was observed that out of top 500 journals, no Indian journal was present. This represents the sorry state of India's research journalism. As far as China is concerned it was represented by a single journal in the Nano sciences. Out of total 500 journals, nearly 90\% were represented by USA and UK; and more than $99 \%$

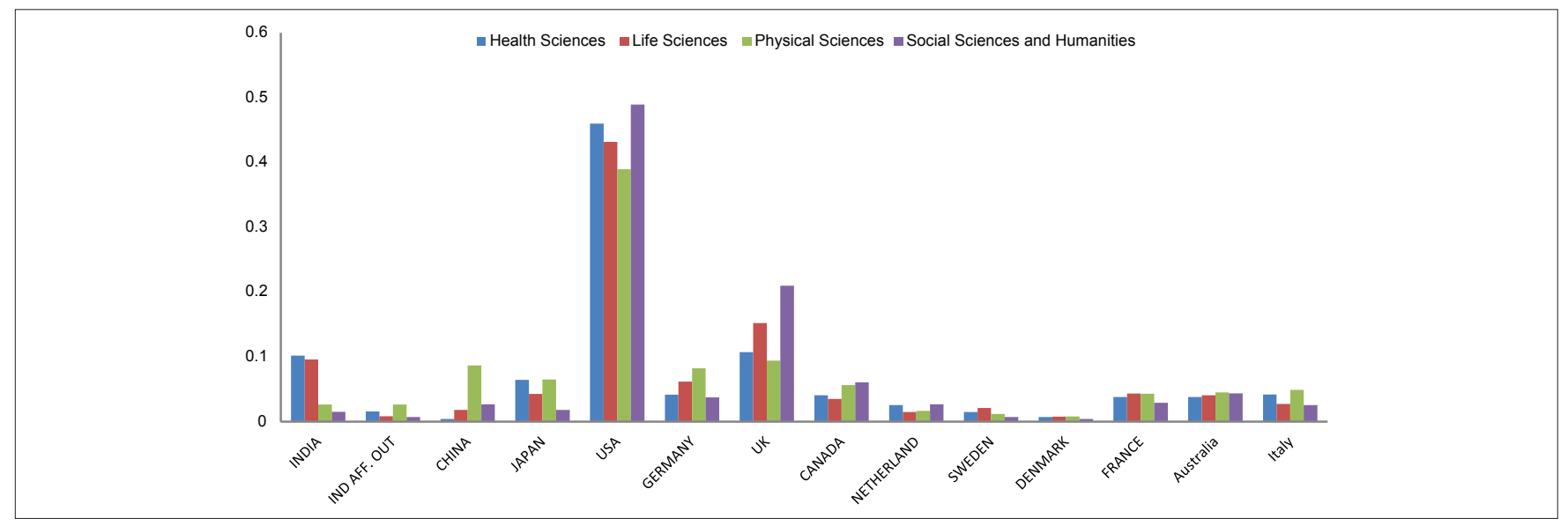

Figure 6: Proportion of Editorial membership of different countries in each subject field 


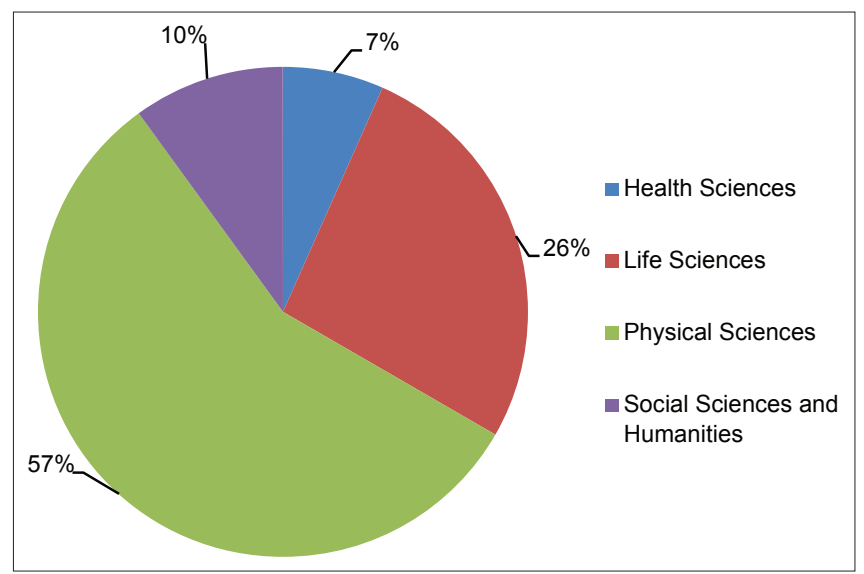

Figure 7: Indian contribution in the each subject field

were represented by elite group of USA, UK, Netherlands, Germany and Switzerland. Representation of Indians in the editorial board membership also exhibits a dismal picture for Indian researchers with only $0.3 \%$ representation out of a total of 14000 odd members. However, if we also include the NRIs the picture becomes a little bright with representation of around $2.24 \%$, which is more than China (1.94\%), France $(1.97 \%)$, Japan $(1.77 \%)$, Netherlands $(1.87 \%)$ and Sweden $(1.55 \%)$. This also indicates that Indians researchers who move abroad have a better chance of networking among the research networks abroad. This also represents the dominance of handful of powerful countries in the representation in the top most journals. Representation of Indian members in the quality of Journal (from SJR) showed them associated with the poorest SJR journals (in top 500); whereas China's representation is in the wide spectrum of the SJRs. Classification of top 500 journals show that $26 \%$ journals were from the field of sciences followed by physical sciences $(22 \%)$, multi-disciplinary $(23 \%)$, social sciences $(13 \%)$ and health sciences (11\%). 57\% of Indian editorial members represented physical sciences, followed by $26 \%$ life sciences. In contrast, NRIs represent humanities by $46 \%$. A strong correlation between board members and the countries scientific output for the year 2011 indicates that the editorial members influence the scientific publications of a country very significantly.

\section{ACKNOWLEDGEMENTS}

Authors are gratefully indebted to Shri Anil Kumar Sharma, Ms. Mala Bahl and Shri Rammi Kapoor for their contribution

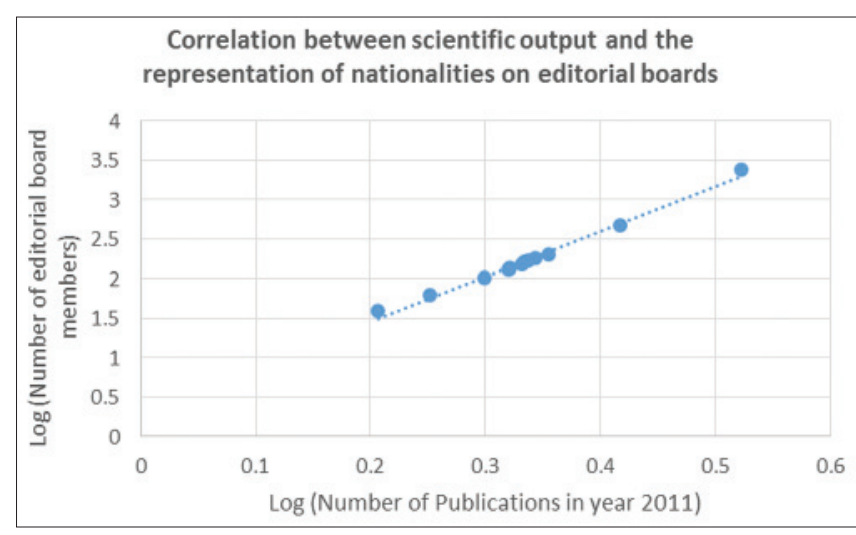

Figure 8: Correlation between scientific output and the representation of nationalities on editorial boards

in the massive data collection without which it would have been a futile exercise. Authors are also thankful to Dr. Parthasarathi Banerjee, Director, CSIR-NISTADS for his valuable suggestions and support.

\section{REFERENCES}

1. Modak JM, Madras G. Scientometric analysis of chemical engineering publications. Curr Sci 2008;94:1265-72.

2. Gupta BM, Bose PR, Kshitij A. Science and technology profile of publications output of India and Germany during 1996-2006: A comparative study. DESIDOC J Libr Inf Technol 2009;29:3-11.

3. Kademani BS, Sagar A, Kumar V, Gupta BM. Mapping of Indian Publications in $\mathrm{S}$ and $\mathrm{T}$ : A Scientometric analysis of publications in science citation index. DESIDOC Bull Inf Technol 2007;27:17-34.

4. Basu A. Using ISI's 'highly cited researchers' to obtain a country level indicator of citation excellence. Scientometrics 2006;68:361-75.

5. Kumar N, Asheolova N. Comparative analysis of scientific out of BRIC countries. Ann Libr Inf Stud 2008;58:228-36.

6. Garciá-Carpintero E, Granadino B, Plaza LM. The representation of nationalities on the editorial boards of international journals and the promotion of the scientific output of the same countries. Scientometrics 2010;84:799-811.

7. Harzing A, Metz I. Practicing what we preach: The geographic diversity of editorial boards. The International Conference of Economics, Business Management and Marketing, Paris, 28-30 June; 2010.

8. Granadino B, Garciá-Carpintero E, Plaza LM. The Spanish presence on boards and editorial boards of scientific journals international instrument for the promotion of our science, Span J Sci Lit 2006;29:398-408.

How to cite this article: Kumar V, Srivastava R. Indian gatekeepers of foreign journals: A preliminary analysis. J Sci Res 2013;2:110-5.

Source of Support: Nil, Conflict of Interest: None declared 